\title{
Glucose Biosensor Based on Immobilization of Glucose Oxidase on Porous Screen Printed Electrodes
}

\author{
Li-Jun Bian, Lu Wang, Yin-Jian Ye, Xiao-Xia Liu* \\ Department of Chemistry, Northeastern University, Shenyang, 110819 \\ *E-mail: xxliu@mail.neu.edu.cn,
}

doi: 10.20964/2017.07.23

Received: 29 March 2017 / Accepted: 18 April 2017 / Published: 12 June 2017

\begin{abstract}
Screen printed electrodes with porous structure (PSPE) were obtained through electrochemical pretreatment. The surface morphology of PSPE exhibited a sponge-like network honeycombed by nano-size cavities. Glucose oxidase (GOD) was immobilized on the surface of PSPE by Nafion. Cyclic voltammetric results revealed that PSPE can facilitate direct electron transfer of GOD. The glucose biosensor based on GOD-PSPE showed linear amperometric responds to glucose in the ranges of 1-8 $\mathrm{mM}$ with high stability.
\end{abstract}

Keywords: screen printed electrode, glucose oxidase, direct electron transfer

\section{$\underline{\text { FULL TEXT }}$}

(C) 2017 The Authors. Published by ESG (www.electrochemsci.org). This article is an open access article distributed under the terms and conditions of the Creative Commons Attribution license (http://creativecommons.org/licenses/by/4.0/). 